\title{
Investigation of Longitudinal Elastic Wave Propagation Through Intersecting Welded bars
}

Ming-Te Liang

Associate Professor, Department of Harbor and River Engineering Taiwan Ocean University, Keelung, Taiwan, 202, R.O.C

Chiou-Jenn Chen

Teaching Assistant, Department of Harbor and River Engineering Taiwan Ocean University, Keelung, Taiwan, 202, R.O.C

Follow this and additional works at: https://jmstt.ntou.edu.tw/journal

Part of the Civil and Environmental Engineering Commons

\section{Recommended Citation}

Liang, Ming-Te and Chen, Chiou-Jenn (2009) "Investigation of Longitudinal Elastic Wave Propagation Through Intersecting Welded bars," Journal of Marine Science and Technology. Vol. 7: Iss. 1, Article 2.

DOI: $10.51400 / 2709-6998.2507$

Available at: https://jmstt.ntou.edu.tw/journal/vol7/iss1/2

This Research Article is brought to you for free and open access by Journal of Marine Science and Technology. It has been accepted for inclusion in Journal of Marine Science and Technology by an authorized editor of Journal of Marine Science and Technology. 


\title{
INVESTIGATION OF LONGITUDINAL ELASTIC WAVE PROPAGATION THROUGH INTERSECTING WELDED BARS
}

\author{
Ming-Te Liang* and Chiou-Jenn Chen**
}

Keywords: Incident wave, Reflection, Transmission.

\begin{abstract}
The main purpose of this paper is to express a general formulation for the theoretical analysis of longitudinal elastic wave propagation through a general and in particular the $\mathrm{T}$ and + junctions. The bar joint is modeled as a rigid block. The bars are assumed to be all of the same thickness but may differ in width and may be of different materials. Elementary theory is applied to investigate the propagation of longitudinal wave. The present study indicates that for a $\mathrm{T}$ junction there would be no transmission of the longitudinal elastic wave. For a +junction there would be no transmission of the longitudinal elastic wave into the perpendicular branches but the transmission into the horizontal bar was happened.
\end{abstract}

\section{INTRODUCTION}

Welding is used extensively in steel structures, space shuttles, aircraft, ships, cars, locomotives and offshore platforms. When these structures are subjected to a sudden seismic or aerodynamic disturbance, the energy of longitudinal elastic wave should be absorbed by the structural joints if structural damage is to be prevented. The fate of longitudinal elastic waves as they propagate through welded intersection joint is thus a very important consideration in structural design for dynamic loading conditions.

Mandel et al. [1] have studied the problem of stress-wave propagation through a rigid right-angle joint by using the method of characteristics, and also experimentally verified their theoretical result. They found that tension and shear in the horizontal bar becomes

Paper Received Jan. 5, 1999. Revised March 17, 1999. Accepted May 3, 1999. Author for Correspondence: Ming-Te Liang.

*Associate Professor, Department of Harbor and River Engineering Taiwan Ocean University, Keelung, Taiwan, 202, R.O.C.

**Teaching Assistant, Department of Harbor and River Engineering Taiwan Ocean University, Keelung, Taiwan, 202, R.O.C. shear and tension in the vertical bar. Desmond [2] found that when a longitudinal stress wave impinges on a junction of three elastic bars where two bars are collinear and the third is noncollinear to the others, a longitudinal stress wave and a flexural (shear) wave are reflected back along the first bar, and stress waves of both types are transmitted into the second and third bars. Simha and Fourney [3] have presented a general formulation for the analysis of stress wave propagation through a junction of rectangular bars, and the dynamic photoelasticity measurement was used for their experimental investigation. They concluded that a longitudinal stress wave in the horizontal bar is not transmitted into the perpendicular branch. It is worth pointing out that there exist a lot of mistakes in the theoretical analysis of Simha and Fourney [3]. The theoretical derivation using the method of Laplace's transform is incorrect at there, such as Eqs. (8), (9), (10), (11), (12), (13) and Appendix A in the paper of Simha and Fourney [3]. The inverse Laplace transform is also not used in Simha and Fourney [3]. The experimental results do not clarify the theoretical result. Wu and Lundberg [4] dealt with harmonic elastic waves in a uniform bar with a straight semi-infinite input section, a bend with constant radius of curvature and a straight semi-infinite output section. The effects of rotary inertia and shear deformation were both neglected. They found that for a sharp $99.9^{\circ}$ bend, an incident extensional wave does not produce a transmitted longitudinal wave at any frequency. For a sharp right-angle bend, the energy flux of the transmitted extensional wave is up to $4 \%$ of the incident extensional wave, depending on the frequency. For a straight bar, the extensional wave is totally transmitted.

In order to correct the formulas derived by Simha and Fourney [3], this paper again presents a general formulation for the theoretical analysis of longitudinal elastic wave propagation around a general junction. First, the theoretical derivation is introduced. Then 
both $\mathrm{T}$ and 十geometrical cases are calculated for checking the theoretical analysis. Finally, the conclusions are made.

\section{THEORETICAL DERIVATION}

In this section, the structures of the derivation is divided into three parts:

I. Transverse waves, II. Longitudinal waves, and III. The special case of welded bars with T-geometry. As for parts I and II, the method of Laplace's transform is applied. As to part III, it is the application of parts I and II.

\section{Transverse waves}

Consider a junction of three elastic plates as shown in Fig. 1. Assume that the steel plate is elastic. For transverse waves, the following equations (Atkins and Hunter [5]) should be satisfied:

$$
\begin{aligned}
& \frac{\partial^{4} y_{j}}{\partial x_{j}^{4}}+\frac{\rho_{j} A_{j}}{E_{j} I_{j}} \frac{\partial^{2} y_{j}}{\partial t^{2}}=0,(j=1,2,3), y_{j}\left(x_{j}, 0\right)=0, \\
& \frac{\partial}{\partial t} y_{j}\left(x_{j}, 0\right)=0
\end{aligned}
$$

where $y_{j}, E_{j}, I_{j}, \rho_{j}$ and $A_{j}$ represent the displacement, Young's modulus, moment of inertia, mass density and cross-sectional area, respectively, and $x$ and $t$ stand for space and time coordinates, respectively.

Let $C_{j}^{2}=\frac{E_{j}}{\rho_{j}}, A_{j}=2 L_{j} t_{j}$, and $I_{j}=\frac{2 t_{j} L_{j}^{3}}{3}$, where $t_{j}$ is the thickness of the steel plate, $2 L_{j}$ is width, and $C_{j}$ is wave speed. Then Eq. (1) can be written as

$$
\frac{\partial^{4} y_{j}}{\partial x_{j}^{4}}+\frac{3}{C_{j}^{2} L_{j}^{2}} \frac{\partial^{2} y_{j}}{\partial t^{2}}=0, y_{j}\left(x_{j}, 0\right)=0, \frac{\partial}{\partial t} y_{j}\left(x_{j}, 0\right)=0 \text { (2) }
$$

The definition of the Laplace transform is

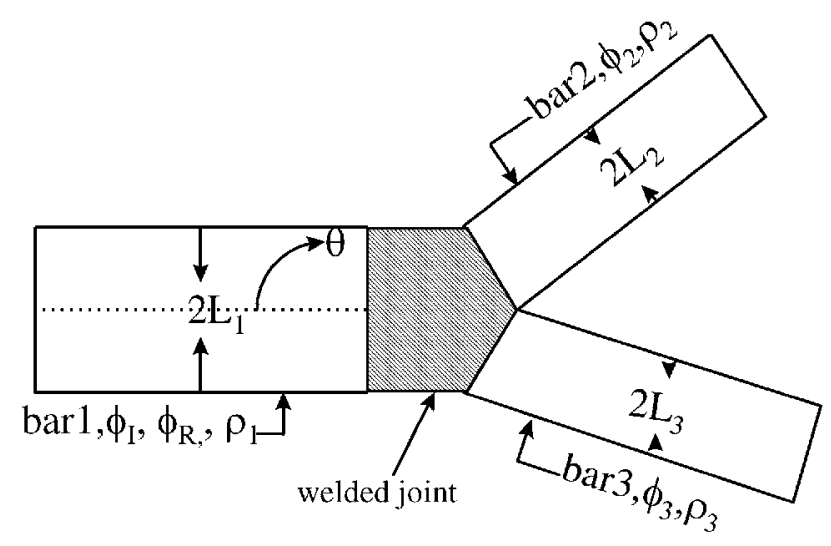

Fig. 1. General sketch of a trifurcated welded bar.

$$
L\left[y_{j}\left(x_{j}, t\right)\right]=\bar{y}\left(x_{j}, p\right)=\int_{0}^{\infty} e^{-p t} y_{j}\left(x_{j}, t\right) d t
$$

After applying the Laplace transform, Eq. (2) becomes

$$
\frac{d^{4} \bar{y}_{j}}{d x_{j}^{4}}+\frac{3 p^{2}}{C_{j}^{2} L_{j}^{2}} \bar{y}_{j}=0
$$

Eq. (4) is

Substituting $\beta_{j}^{4}=\frac{3}{4 C_{j}^{2} L_{j}^{2}}$ and $i^{2}=-1$, the solution of

$$
\begin{aligned}
\bar{y}_{j}\left(x_{j}, p\right) & =A_{j}(p) e^{-(1+i) \beta_{j} \sqrt{p} X_{j}}+B_{j}(p) e^{-(1-i) \beta_{j} \sqrt{p} X_{j}} \\
& +C_{j}(p) e^{(1+i) \beta_{j} \sqrt{p} X_{j}}+D_{j}(p) e^{(1-i) \beta_{j} \sqrt{p} X_{j}}
\end{aligned}
$$

For the boundedness of the solution, let $C_{j}(p)=D_{j}$ $(p)=0$. Thus, Eq. (5) becomes

$$
\bar{y}_{j}\left(x_{j}, p\right)=A_{j}(p) e^{-(1+i) \beta_{j} \sqrt{p} X_{j}}+B_{j}(p) e^{-(1-i) \beta_{j} \sqrt{p} X_{j}}
$$

The moments and shear forces are given by

$$
\bar{M}_{j}=E_{j} I_{j}\left[\frac{d^{2} \bar{y}_{j}}{d x_{j}^{2}}\right]_{x_{j}=0}
$$

and

$$
\bar{Q}_{j}=E_{j} I_{j}\left[\frac{d^{3} \bar{y}_{j}}{d x_{j}^{3}}\right]_{x_{j}=0}
$$

Using Eqs.(7) and (8) yields

$$
\begin{aligned}
& A_{j}(p)=\frac{1}{4 E_{j} I_{j} \beta_{j}^{2}}\left[\frac{\bar{Q}_{j}}{\beta_{j} p^{3 / 2}}+(1-i) \frac{\bar{M}_{j}}{p}\right] \\
& B_{j}(p)=\frac{1}{4 E_{j} I_{j} \beta_{j}^{2}}\left[\frac{\bar{Q}_{j}}{\beta_{j} p^{3 / 2}}+(1+i) \frac{\bar{M}_{j}}{p}\right]
\end{aligned}
$$

There are three unknowns, $X, Y$ and $\theta$ as shown in Fig. 2, where $X$ is the horizontal displacement, $Y$ is the vertical displacement and $\theta$ is the rotational angle, which should satisfy the following equations:

$$
\begin{aligned}
& {\left[\frac{d \bar{y}_{j}}{d x_{j}}\right]_{x_{j}=0}=-\bar{\theta}} \\
& {\left[\bar{y}_{j}\right]_{x_{j}=0}=-\bar{X} \sin \theta_{j}-\bar{Y} \cos \theta_{j}-\bar{\theta} d_{j}}
\end{aligned}
$$

where $\theta_{j}$ is the bar angle, and $d_{j}$ is the moment arm of shear force $Q_{j}$ (see Fig. 2). Substituting Eqs. (9) and (10) into Eqs. (12) and (11) yield

$$
\frac{1}{2 E_{j} I_{j} \beta_{j}^{2}}\left[\frac{\bar{Q}_{j}}{\beta_{j} p^{3 / 2}}+\frac{\bar{M}_{j}}{p}\right]=-\bar{X} \sin \theta_{j}-\bar{Y} \cos \theta_{j}-\bar{\theta} d_{j}
$$




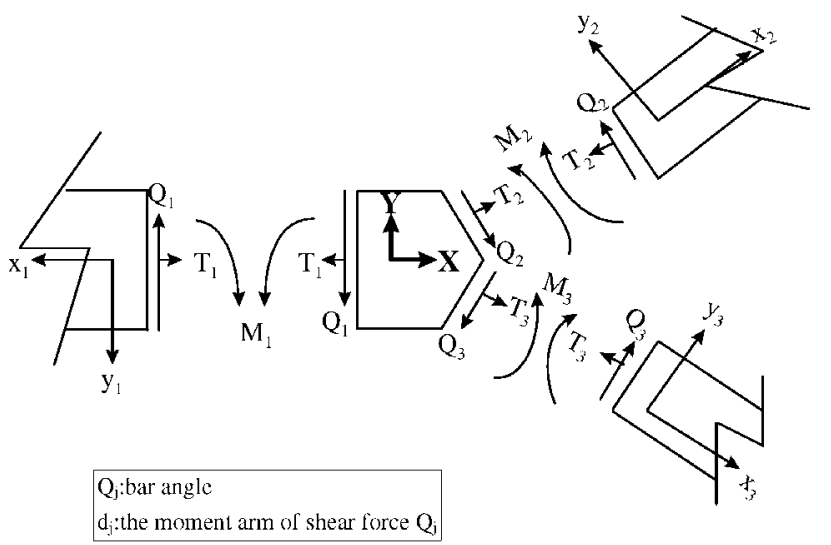

Fig. 2. Free-body diagram and systems of coordinates of a trifurcated welding bar.

$$
\frac{1}{2 E_{j} I_{j} \beta_{j}}\left[\frac{\bar{Q}_{j}}{\beta_{j} p}+2 \frac{\bar{M}_{j}}{\sqrt{p}}\right]=\bar{\theta}
$$

\section{Longitudinal waves}

Similarly, the longitudinal waves should satisfy the following equations (Atkins and Hunter 1975, Simha and Fourney [3]):

$$
\frac{\partial^{2} U_{j}}{\partial x_{j}^{2}}-\frac{1}{C_{j}^{2}} \frac{\partial^{2} U_{j}}{\partial t^{2}}=0
$$

with the initial conditions $U_{j}\left(x_{j}, 0\right)=0$ and $\frac{\partial U_{j}\left(x_{j}, 0\right)}{\partial t}=0$, where $U_{j}$ is the displacement of longitudinal waves.

As illustrated in Fig. $1, \phi_{I}$ and $\phi_{R}$ indicate, respectively, the incident and reflected longitudinal waves in bar $1 ; \phi_{2}$ and $\phi_{3}$ denote the transmitted longitudinal waves in bar 2 and bar 3, respectively. Their relationships to each other can be expressed as

$$
\begin{aligned}
& U_{1}\left(x_{1}, t\right)=\phi_{I}\left(t+\frac{x_{1}}{C_{1}}\right)+\phi_{R}\left(t-\frac{x_{1}}{C_{1}}\right) \\
& U_{2}\left(x_{2}, t\right)=\phi_{2}\left(t-\frac{x_{2}}{C_{2}}\right) \\
& U_{3}\left(x_{3}, t\right)=\phi_{3}\left(t-\frac{x_{3}}{C_{3}}\right)
\end{aligned}
$$

Applying the Laplace transform to Eq. (15) gives

$$
\frac{d^{2} \bar{U}_{j}}{d x_{j}^{2}}-\left(\frac{p^{2}}{C_{j}^{2}}\right) \bar{U}_{j}=0
$$

The solution of Eq. (19) is

$$
\bar{U}\left(x_{j}, p\right)=C_{1}\left(x_{j}, p\right) e^{\left(\frac{p}{C_{j}}\right) x_{j}}+C_{2}\left(x_{j}, p\right) e^{-\left(\frac{p}{C_{j}}\right) x_{j}}
$$

For the boundedness of the solution, let $C_{1}\left(x_{j}, p\right)=$ 0 . Thus,

$$
\bar{U}\left(x_{j}, p\right)=C_{2}\left(x_{j}, p\right) e^{-\left(\frac{p}{C_{j}}\right) x_{j}}
$$

The Laplace transform of the joint boundary conditions is

$$
\left[\bar{U}_{j}\right]_{x_{j}=0}=-\bar{X} \cos \theta_{j}+\bar{Y} \sin \theta_{j}
$$

Substituting Eq. (22) into Eq. (21), we obtain

$$
\bar{U}\left(x_{j}, p\right)=\left(-\bar{X} \cos \theta_{j}+\bar{Y} \sin \theta_{j}\right) e^{-\left(\frac{p}{C_{j}}\right) x_{j}}
$$

The substitution of Eq. (16) into Eq. (22) yields

$$
\left(\bar{\phi}_{1}+\bar{\phi}_{R}\right)=-\bar{X}
$$

Inserting Eqs. (17) and (18) into Eq. (22) leads to

$$
\bar{\phi}_{j}=-\bar{X} \cos \theta_{j}+\bar{Y} \sin \theta_{j},(j=2,3)
$$

The relationship of stress and internal force can be expressed as

$$
T_{j}=E_{j} A_{j}\left(\frac{\partial U_{j}}{\partial x_{j}}\right),(j=1,2,3)
$$

where $A_{j}=2 L_{j} t_{j}, A_{j}$ is area, and $t_{j}$ is thickness. Differentiating Eq. (23) with respect to $x_{j}$ and substituting the resultant into Eq. (26) yields

$$
\bar{T}_{j}=-2 p \rho_{j} C_{j} L_{j} t_{j} \bar{\phi}_{j},(j=1,2,3)
$$

Since the horizontal force, the vertical force and the moment (see Fig. 2) are in equilibrium, we get

$$
\begin{aligned}
& \sum_{j=1,2,3}\left(\bar{T}_{j} \cos \theta_{j}-\bar{Q}_{j} \sin \theta_{j}\right)+m p^{2} \bar{X}=0 \\
& \sum_{j=1,2,3}\left(\bar{T}_{j} \sin \theta_{j}-\bar{Q}_{j} \cos \theta_{j}\right)-m p^{2} \bar{Y}=0 \\
& \sum_{j=1,2,3}\left(\bar{M}_{j}+e_{j} \bar{T}_{j}+d_{j} \bar{Q}_{j}\right)-I p^{2} \bar{\theta}=0
\end{aligned}
$$

where $e_{j}$ is the moment arm of axial force $T_{j}, m=4 \rho L^{2}$ is the mass of per unit length of the joint and $I=\frac{16 \rho t^{5}}{3}$ is the moment of inertia of the welded joint. Finally, the 15 unknowns can be solved from 15 equations obtained from Eqs. (13), (14), (24), (25), (27), (28), (29) and (30).

\section{The special case}

Now, consider the case of welded bars with Tgeometry (see Fig. 3). Assume each bar is constituted 


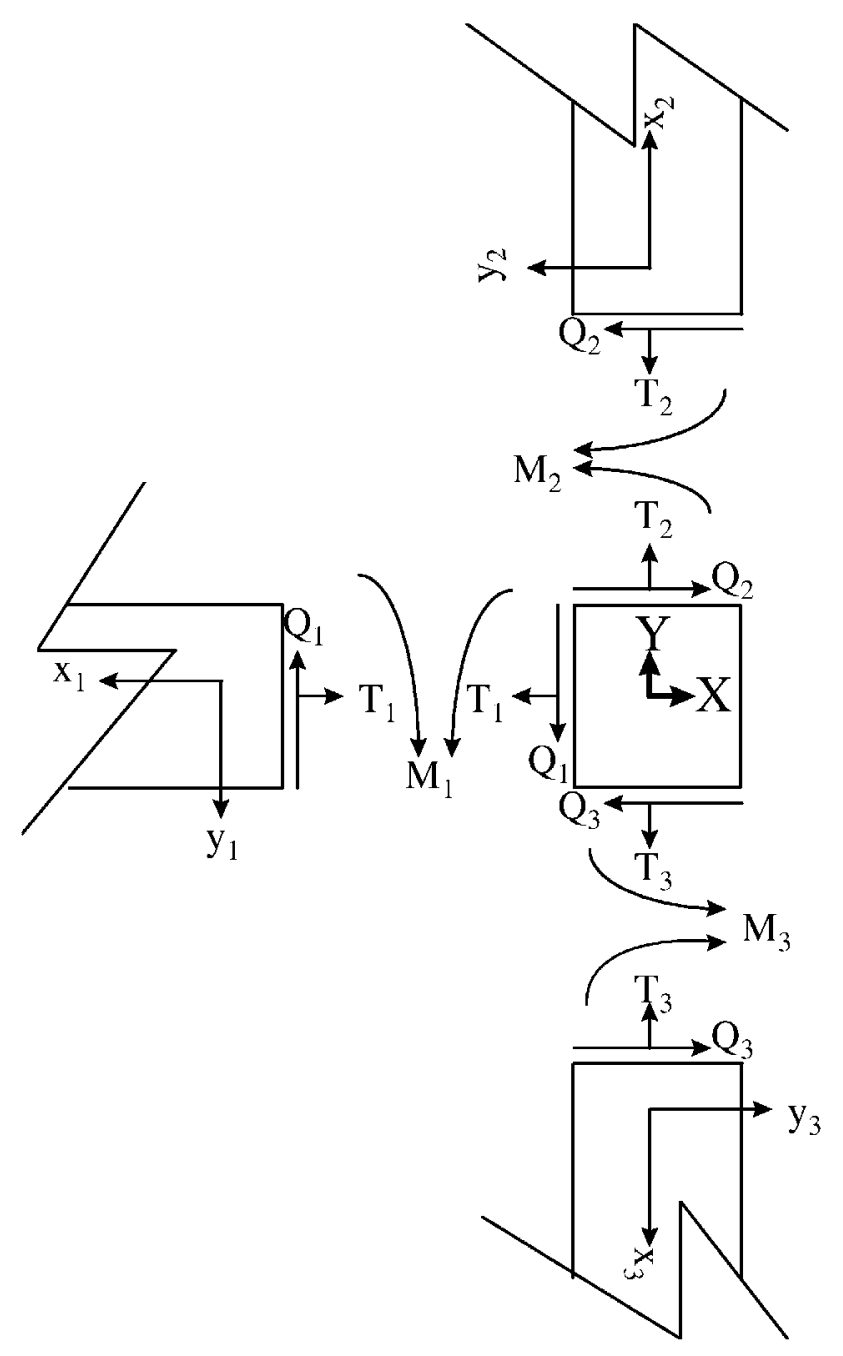

Fig. 3. Free-body diagram of the T-type steel plate. $Q_{1,2,3}$ represent the shear forces, $T_{1,2,3}$ the axial forces and $M_{1,2,3}$ the moment . $\theta_{1}=0^{\circ}$, $\theta_{2}=90^{\circ}, \theta_{3}=270^{\circ}$, (see Fig. 1 for an explanation of $\theta$ ).

of the same material and has the same material properties as listed in Table 1.

Let coefficient $\alpha=\frac{\sqrt{3}}{2}$ (see Atkins and Hunter [5]), substituting the appropriate values (see Fig. 4) into Eqs.(13) and (14) and Eqs. (24) (30) gives:

$$
\begin{aligned}
& \bar{\phi}_{R}+\left(\frac{\bar{T}_{1}}{4 \rho C p L^{2}}\right)=\bar{\phi}_{I} \\
& \bar{\phi}_{2}+\left(\frac{\bar{T}_{2}}{4 \rho C p L^{2}}\right)=0 \\
& \bar{\phi}_{3}+\left(\frac{\bar{T}_{3}}{4 \rho C p L^{2}}\right)=0 \\
& \bar{T}_{1}-\bar{Q}_{2}+\bar{Q}_{3}+8 \rho L^{3} p^{2} \bar{X}=0 \\
& \bar{Q}_{1}-\bar{T}_{2}+\bar{T}_{3}+8 \rho L^{3} p^{2} \bar{Y}=0
\end{aligned}
$$

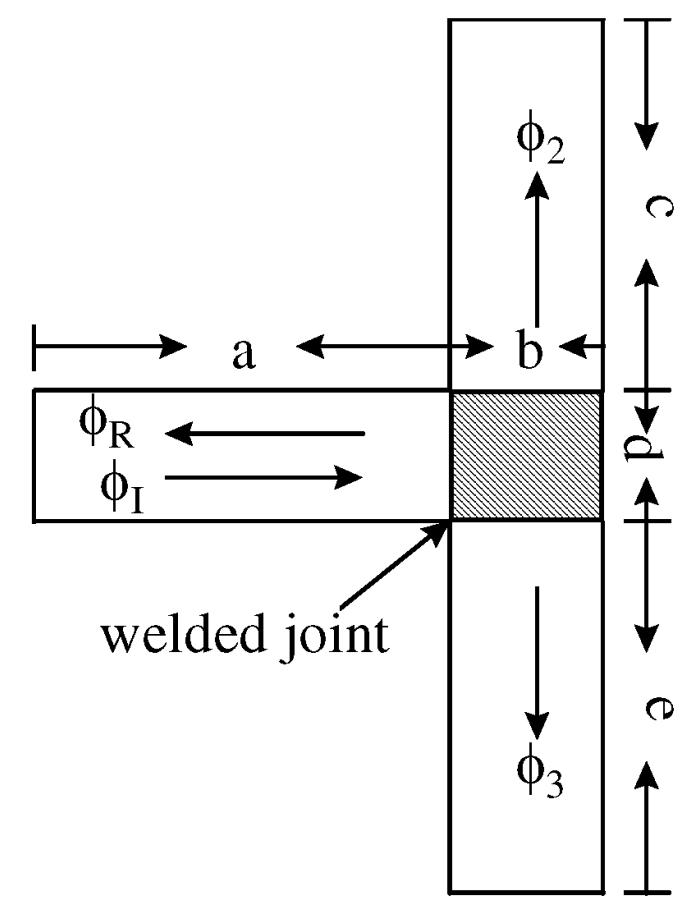

Fig. 4. T-type steel plate dimensions. The plate is $0.025 \mathrm{~m}$ thick. Other dimensions are as follows: $\mathrm{a}=1.2 \mathrm{~m}, \mathrm{~b}=\mathrm{d}=0.025 \mathrm{~m}, \mathrm{c}=\mathrm{e}=1.2 \mathrm{~m}$.

$$
\bar{M}_{1}+\bar{M}_{2}+\bar{M}_{3}-L\left(\bar{Q}_{3}+\bar{Q}_{2}-\bar{Q}_{1}\right)+\frac{16 \rho L^{5} p^{2} \bar{\theta}}{3}=0
$$$$
\frac{3}{8 E L^{4}}\left[\left(\frac{C L}{\alpha p}\right)^{3 / 2} \bar{Q}_{1}+\left(\frac{C L}{\alpha p}\right) \bar{M}_{1}\right]=-\bar{Y}-L \bar{\theta}
$$

$\frac{3}{8 E L^{4}}\left[\left(\frac{C L}{\alpha p}\right)^{3 / 2} \bar{Q}_{2}+\left(\frac{C L}{\alpha p}\right) \bar{M}_{2}\right]=-\bar{X}-L \bar{\theta}$

$\frac{3}{8 E L^{4}}\left[\left(\frac{C L}{\alpha p}\right)^{3 / 2} \bar{Q}_{3}+\left(\frac{C L}{\alpha p}\right) \bar{M}_{3}\right]=\bar{X}-L \bar{\theta}$

$\frac{3}{8 E L^{4}}\left[\left(\frac{C L}{\alpha p}\right) \bar{Q}_{1}+2\left(\frac{C L}{\alpha p}\right)^{1 / 2} \bar{M}_{1}\right]-\bar{\theta}=0$

$\frac{3}{8 E L^{4}}\left[\left(\frac{C L}{\alpha p}\right) \bar{Q}_{2}+2\left(\frac{C L}{\alpha p}\right)^{1 / 2} \bar{M}_{2}\right]-\bar{\theta}=0$

$\frac{3}{8 E L^{4}}\left[\left(\frac{C L}{\alpha p}\right) \bar{Q}_{3}+2\left(\frac{C L}{\alpha p}\right)^{1 / 2} \bar{M}_{3}\right]-\bar{\theta}=0$

$\bar{\phi}_{2}-\bar{Y}=0$

$\bar{\phi}_{3}+\bar{Y}=0$

and $-\bar{\phi}_{R}-\bar{X}=\bar{\phi}_{I}$ 
Table 1. Physical characteristics of the steel plate

\begin{tabular}{cccccc}
\hline material & unit weight & density & Young's modulus & shear modulus & \multicolumn{2}{c}{ Poisson's ratio } \\
properties & $\gamma$ & $\rho$ & $\mathrm{E}$ & $\mathrm{G}$ & $v$ \\
\hline unit & $\left(\mathrm{kN} / \mathrm{m}^{3}\right)$ & $\left(\mathrm{kg} / \mathrm{m}^{3}\right)$ & $(\mathrm{Gpa})$ & $(\mathrm{Gpa})$ & - \\
values & 77 & 7850 & 200 & 80 & 0.3 \\
\hline
\end{tabular}

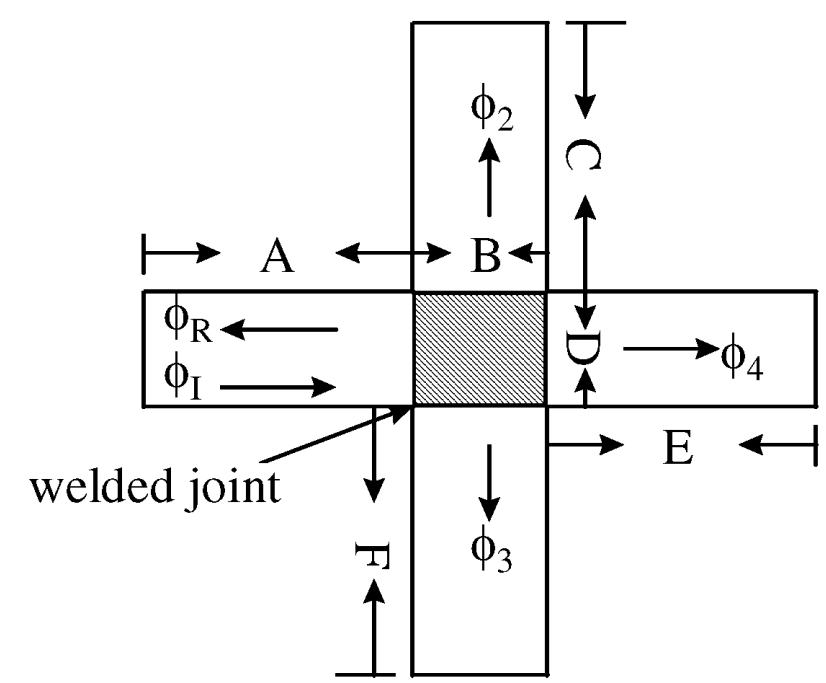

Fig. 5. 十-type steel plate dimensions. The plate is $0.025 \mathrm{~m}$ thick. Other dimensions are as follows: $\mathrm{A}=1.2 \mathrm{~m}, \mathrm{~B}=0.025 \mathrm{~m}, \mathrm{C}=1.2 \mathrm{~m}, \mathrm{D}=$ $0.025 \mathrm{~m}, \mathrm{E}=1.2 \mathrm{~m}, \mathrm{~F}=1.2 \mathrm{~m}$.

The incident wave $\bar{\phi}_{I}$ is known. Thus from Eqs. (31) (45), the values of $\bar{M}_{1}, \bar{M}_{2}, \bar{M}_{3}, \bar{Q}_{1}, \bar{Q}_{2}, \bar{Q}_{3}, \bar{T}_{1}, \bar{T}_{2}, \bar{T}_{3}, \bar{\phi}_{R}$, $\bar{\phi}_{2}, \bar{\phi}_{3}, \bar{X}, \bar{Y}$ and $\bar{\theta}$ can be determined and the following equations can thereby be derived (see Appendix)

$$
\begin{aligned}
& \bar{\phi}_{3}=-\bar{\phi}_{2} \\
& \bar{\phi}_{2}=0
\end{aligned}
$$

Since $\bar{\phi}_{2}=\bar{\phi}_{3}=0$, the inverse Laplace transform need not be used. We know that for a $T$ junction there would be no transmission of the longitudinal stress wave in the vertical bar, because boundary conditions are satisfied the condition of compatibility and both bar 2 and bar 3 are symmetrical. Thus, the coupling action is occurred and the infinitesimal values of transmitted longitudinal wave in the vertical bar does not exist.

In this paper, we adopt the bar with finite length as example. The first single received from sensor was taken for analysis. The longitudinal wave is only to be discussed. As to the action time, we take the time when the first incident wave is not yet arrived at the end point of bar. Thus, the interference due to the other reflection waves and diffraction waves can be avoided for analysis.

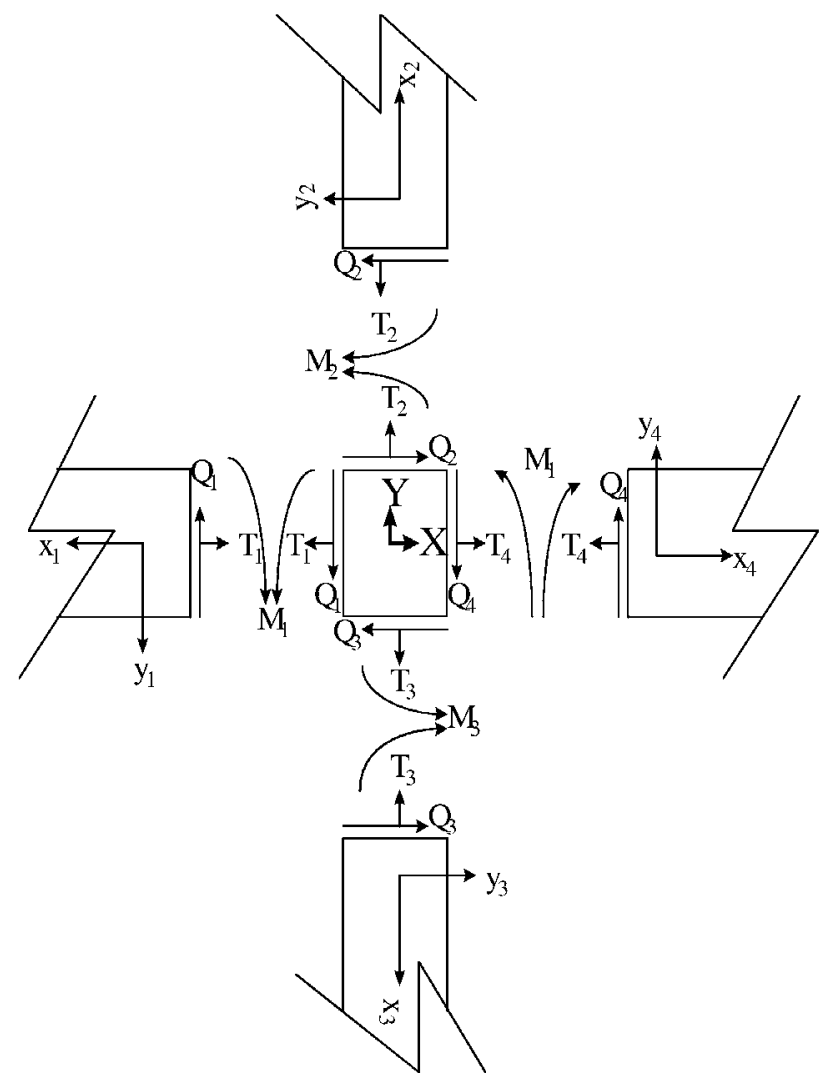

Fig. 6. Free-body diagram of the 十-type steel plate. $Q_{1,2,3,4}$ represent the shear forces, $T_{1,2,3,4}$ the axial forces and $M_{1,2,3,4}$ the moment $\theta_{1}=$ $0^{\circ}, \theta_{2}=90^{\circ}, \theta_{3}=270^{\circ}, \theta_{4}=180^{\circ}$, (see Fig. 1 for an explanation of $\theta$ ).

\section{EXTENDED APPLICATION OF THE MODEL}

In engineering practice, multiple bars are usually welded together. In this section, the $\mathrm{T}$ geometry case developed above is extended to the $十$ geometry case (see Fig. 5 and Fig. 6).

Extending Eqs. (13) and (14)and Eqs. (24) (30), the following equations can be added for $j=4$ :

$$
\begin{aligned}
& \bar{\phi}_{4}+\left(\frac{\bar{T}_{4}}{2 p \rho_{4} C_{4} L_{4} t_{4}}\right)=0 \\
& \frac{1}{2 E_{4} I_{4} \beta_{4}^{2}}\left[\frac{\bar{Q}_{4}}{\beta_{4} p^{3 / 2}}+\frac{\bar{M}_{4}}{p}\right]+\bar{X} \sin \theta_{4}+\bar{Y} \cos \theta_{4}+\bar{\theta} d_{4}=0
\end{aligned}
$$




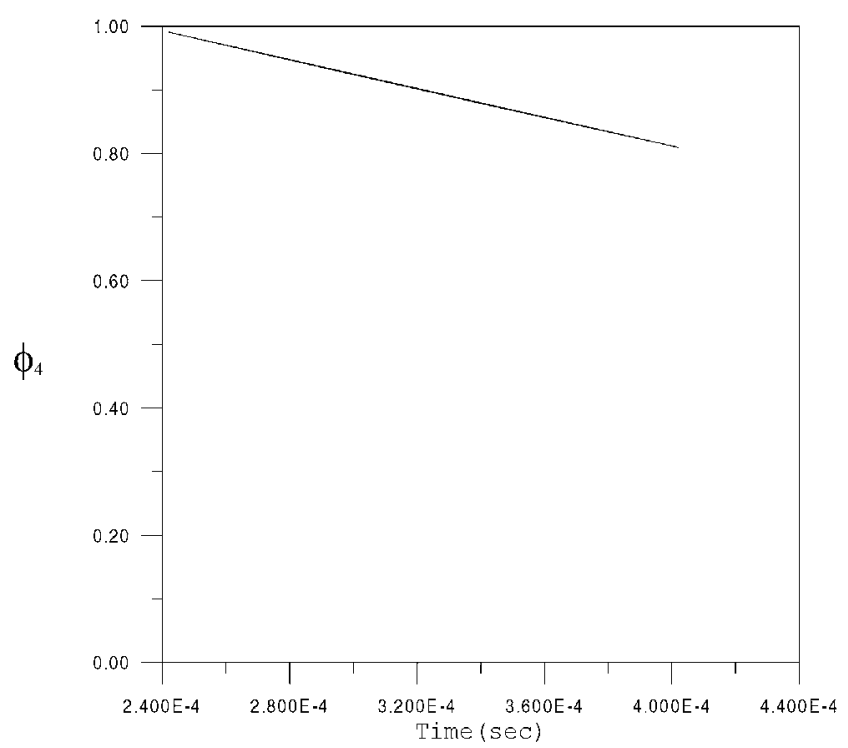

Fig. 7. Values of transmitted longitudinal elastic waves in the horizontal welded bar for the 十-type steel plate.

$\frac{1}{2 E_{4} I_{4} \beta_{4}^{2}}\left[\frac{\bar{Q}_{4}}{\beta_{4} p}+2 \frac{\bar{M}_{4}}{\sqrt{p}}\right]-\bar{\theta}=0$

$\bar{\phi}_{4}+\bar{X} \cos \theta_{4}-\bar{Y} \sin \theta_{4}=0$

Substitution of the appropriate values (see Fig. 5 and Fig. 6) into Eqs. (13) and (14), Eqs. (24) (30) and Eqs. (48) (51) yields

$$
\begin{aligned}
& \bar{\phi}_{R}+\left(\frac{\bar{T}_{1}}{4 \rho C p L^{2}}\right)=\bar{\phi}_{I} \\
& \bar{\phi}_{2}+\left(\frac{\bar{T}_{2}}{4 \rho C p L^{2}}\right)=0 \\
& \bar{\phi}_{3}+\left(\frac{\bar{T}_{3}}{4 \rho C p L^{2}}\right)=0 \\
& \bar{\phi}_{4}+\left(\frac{\bar{T}_{4}}{4 \rho C p L^{2}}\right)=0 \\
& \bar{T}_{1}-\bar{Q}_{2}+\bar{Q}_{3}-\bar{T}_{4}+8 \rho L^{3} p^{2} \bar{X}=0 \\
& \bar{Q}_{1}-\bar{T}_{2}+\bar{T}_{3}-\bar{Q}_{4}+8 \rho L^{3} p^{2} \bar{Y}=0 \\
& \bar{M}_{1}+\bar{M}_{2}+\bar{M}_{3}+\bar{M}_{4}-L\left(\bar{Q}_{3}+\bar{Q}_{2}-\bar{Q}_{1}-\bar{Q}_{4}\right) \\
& +\frac{16 \rho L^{5} p^{2} \bar{\theta}}{3}=0 \\
& \frac{3}{8 E L^{4}}\left[\left(\frac{C L}{\alpha p}\right)^{3 / 2} \bar{Q}_{1}+\left(\frac{C L}{\alpha p}\right) \bar{M}_{1}\right]=-\bar{Y}-L \bar{\theta}
\end{aligned}
$$

$$
\begin{aligned}
& \frac{3}{8 E L^{4}}\left[\left(\frac{C L}{\alpha p}\right)^{3 / 2} \bar{Q}_{2}+\left(\frac{C L}{\alpha p}\right)^{M_{2}}\right]=-\bar{X}-L \bar{\theta} \\
& \frac{3}{8 E L^{4}}\left[\left(\frac{C L}{\alpha p}\right)^{3 / 2} \bar{Q}_{3}+\left(\frac{C L}{\alpha p}\right)^{M_{3}}\right]=\bar{X}-L \bar{\theta} \\
& \frac{3}{8 E L^{4}}\left[\left(\frac{C L}{\alpha p}\right)^{3 / 2} \bar{Q}_{4}+\left(\frac{C L}{\alpha p}\right)^{M_{4}}\right]=\bar{Y}-L \bar{\theta} \\
& \frac{3}{8 E L^{4}}\left[\left(\frac{C L}{\alpha p}\right) \bar{Q}_{1}+2\left(\frac{C L}{\alpha p}\right)^{1 / 2} \bar{M}_{1}\right]-\bar{\theta}=0 \\
& \frac{3}{8 E L^{4}}\left[\left(\frac{C L}{\alpha p}\right) \bar{Q}_{2}+2\left(\frac{C L}{\alpha p}\right)^{1 / 2} \bar{M}_{2}\right]-\bar{\theta}=0 \\
& \frac{3}{8 E L^{4}}\left[\left(\frac{C L}{\alpha p}\right) \bar{Q}_{3}+2\left(\frac{C L}{\alpha p}\right)^{1 / 2} \bar{M}_{3}\right]-\bar{\theta}=0 \\
& \frac{3}{8 E L^{4}}\left[\left(\frac{C L}{\alpha p}\right) \bar{Q}_{4}+2\left(\frac{C L}{\alpha p}\right)^{1 / 2} \bar{M}_{4}\right]-\bar{\theta}=0 \\
& \bar{\phi}_{2}-\bar{Y}=0 \\
& \bar{\phi}_{3}+\bar{Y}=0 \\
& \bar{\phi}_{4}-\bar{X}=0 \\
& -\bar{\phi}_{R}-\bar{X}=\bar{\phi}_{I}
\end{aligned}
$$

Since $\bar{\phi}_{I}$ is given, from Eqs. (52) (70), the unknowns $\bar{M}_{1}, \bar{M}_{2}, \bar{M}_{3}, \bar{M}_{4}, \bar{Q}_{1}, \bar{Q}_{2}, \bar{Q}_{3}, \bar{Q}_{4}, \bar{T}_{1}, \bar{T}_{2}, \bar{T}_{3}, \bar{T}_{4}, \bar{\phi}_{R}, \bar{\phi}_{2}, \bar{\phi}_{3}$, $\bar{\phi}_{4}, \bar{X}, \bar{Y}$ and $\bar{\theta}$ can be calculated. Here we are concerned with the values of $\bar{\phi}_{2}, \bar{\phi}_{3}$ and $\bar{\phi}_{4}$ for the transmitted longitudinal elastic waves. As before, the following equations can be derived (see Appendix):

$$
\begin{aligned}
& \bar{\phi}_{3}=-\bar{\phi}_{2} \\
& \bar{\phi}_{2}=0 \\
& \bar{\phi}_{4}=-\bar{W}(p) p \bar{\phi}_{I}
\end{aligned}
$$

where

$$
\bar{W}(p)=\frac{\left(\frac{C L}{\alpha p}\right)^{3 / 2}}{\left[\frac{4}{3} C L^{2}+\frac{L p^{2}}{C}\left(\frac{C L}{\alpha p}\right)^{3 / 2}+\left(\frac{C L}{\alpha p}\right)^{3 / 2}\right]}
$$

For convenience, the original positive $x_{1}$ direction of $\bar{\phi}_{I}$ is reversed. Thus, Eq. (73) becomes

$$
\bar{\phi}_{T}=\bar{W}(p) p \bar{\phi}_{I}
$$


Applying the convolution integral to Eq. (75) yields

$$
\phi_{T}=\int_{0}^{t} W\left(t-t^{\prime}\right) \frac{d \phi_{I}\left(t^{\prime}\right)}{d t^{\prime}} d t^{\prime}
$$

where

$$
\begin{aligned}
& W(t) \equiv L^{-1}[\bar{W}(p)] \\
& \frac{d \phi}{d t} \equiv \delta(t) \\
& \tau=\frac{\alpha}{C L} \\
& W(t)=X\left(\frac{t}{\tau}\right)
\end{aligned}
$$

and $X\left(\frac{t}{\tau}\right)=X(x)$

Using the Laplace transform on Eq. (81) gives

$$
\begin{aligned}
\bar{X}(s) & =\int_{0}^{\infty} X(x) e^{-s x} d x \\
& =\frac{C L \alpha s^{1 / 2}}{s^{1 / 2}\left(C L^{3} s^{2}+C L^{2} s^{3 / 2}+\alpha^{2}\right)} \\
& =s^{-1 / 2} \bar{Q}\left(s^{1 / 2}\right)
\end{aligned}
$$

Applying the inverse Laplace transform to Eq. (82) gives

$$
\begin{aligned}
X(x) & =\frac{1}{(\pi x)^{1 / 2}} \int_{0}^{\infty} e^{-\frac{u^{2}}{4 x}} Q(u) d u \\
& =0.8663 e^{1598.9762 x}(1-\operatorname{erf}(39.9872 \sqrt{x})) \\
& +55.582 e^{0.3878 x}(1-\operatorname{erf}(0.6227 \sqrt{x})) \\
& -\operatorname{Re}[(18.07+32.276 i) W(0.8481 \sqrt{x}+0.4936 \sqrt{x} i)] \\
& -e^{-0.4756 x}(36.14 \cos 0.8372 x+64.552 \sin 0.8372 x)
\end{aligned}
$$
yields

Finally, the substitution of Eq. (82) into Eq. (76)

$$
\phi_{T}=\int_{0}^{t} X\left[\left(t-t^{\prime}\right) / \tau\right] \frac{d \phi_{I}\left(t^{\prime}\right)}{d t^{\prime}} d t^{\prime}
$$

Following Achenback [6], we have

$$
\int_{a}^{b} h(x) \delta^{(n)}\left(x-x^{\prime}\right) d x^{\prime}=\left\{\begin{array}{l}
h^{n}(x), x \in(a, b) \\
0, x \notin(a, b)
\end{array}\right.
$$

The $x$ term in Eq. (83) is simply replaced by $t$ :

$$
\begin{aligned}
X(t) & =0.8663 e^{1598.9762 t}(1-\operatorname{erf}(39.9872 \sqrt{t})) \\
& +55.582 e^{0.3878 x}(1-\operatorname{erf}(0.6227 \sqrt{t})) \\
& -\operatorname{Re}[(18.07+32.276 i) W(0.8481 \sqrt{t}+0.4936 \sqrt{t} i)] \\
& -e^{-0.4756 x}(36.14 \cos 0.8372 t+64.552 \sin 0.8372 t)
\end{aligned}
$$

Table 2. Values of transmitted longitudinal elastic waves in 十-type steel plate

\begin{tabular}{ccccc}
\hline $\begin{array}{c}\text { Action time } \\
t(\mathrm{sec})\end{array}$ & $\begin{array}{c}\text { The transformed } \\
\text { action time } t / \tau(\mathrm{sec})\end{array}$ & $\begin{array}{c}\text { The values of } \\
\left(\phi_{2}\right)\end{array}$ & $\begin{array}{c}\text { transmitted longitudinal elastic waves } \\
\left(\phi_{3}\right)\end{array}$ \\
\hline $2.42 \times 10^{-4}$ & 0.0176 & 0 & 0 & 0.9909 \\
$2.50 \times 10^{-4}$ & 0.0182 & 0 & 0 & 0.9815 \\
$2.58 \times 10^{-4}$ & 0.0188 & 0 & 0 & 0.9722 \\
$2.66 \times 10^{-4}$ & 0.0194 & 0 & 0 & 0.9630 \\
$2.74 \times 10^{-4}$ & 0.0200 & 0 & 0 & 0.9538 \\
$2.82 \times 10^{-4}$ & 0.0205 & 0 & 0 & 0.9446 \\
$2.90 \times 10^{-4}$ & 0.0211 & 0 & 0 & 0.9354 \\
$2.98 \times 10^{-4}$ & 0.0217 & 0 & 0 & 0.9263 \\
$3.06 \times 10^{-4}$ & 0.0223 & 0 & 0 & 0.9172 \\
$3.14 \times 10^{-4}$ & 0.0229 & 0 & 0 & 0.9081 \\
$3.22 \times 10^{-4}$ & 0.0235 & 0 & 0 & 0.8990 \\
$3.30 \times 10^{-4}$ & 0.0240 & 0 & 0 & 0.8900 \\
$3.38 \times 10^{-4}$ & 0.0246 & 0 & 0 & 0.8809 \\
$3.46 \times 10^{-4}$ & 0.0252 & 0 & 0 & 0.8719 \\
$3.54 \times 10^{-4}$ & 0.0257 & 0 & 0 & 0.8630 \\
$3.62 \times 10^{-4}$ & 0.0264 & 0 & 0 & 0.8540 \\
$3.70 \times 10^{-4}$ & 0.0270 & 0 & 0 & 0.8451 \\
$3.78 \times 10^{-4}$ & 0.0275 & 0 & 0 & 0.8362 \\
$3.86 \times 10^{-4}$ & 0.0281 & 0 & 0 & 0.8273 \\
$3.94 \times 10^{-4}$ & 0.0287 & 0 & 0 & 0.8185 \\
$4.02 \times 10^{-4}$ & 0.0293 & 0 & 0 & 0.8097 \\
\hline
\end{tabular}


Substituting the t values into Eq. (86) and using Table 1 and the appropriate formulas in Abramowitz and Stegum [7] yields Table 2. From Table 2, Fig. 7 can be plotted. It is obvious that there is no transmission into the vertical welding bars. However, the maximum values of the longitudinal elastic wave transmitted into the horizontal bar are about 99\% (See Table 2 and Fig. 7). This result is very close to the result obtained by $\mathrm{Wu}$ and Lundberg[4].

\section{CONCLUSIONS}

The incorrect formulas, such as Eqs.(8), (9), (10), (11), (12) and (13), derived by Simha and Fourney [3] now have been corrected as Eqs. (9), (10), (11), (12), (13) and (14) in this paper,repectively.

When a horizontal force is applied to the horizontal bar in a $T$ geometry configuration (Figs. $3 \& 4$ ), the longitudinal elastic wave is not transmitted along the vertical bars. This phenomenon is due to the boundary conditions which are satisfying the condition of compatibility and both bar 2 and bar 3 symmetrical. Thus, the coupling action is happened and the infinitesimal values of transmitted longitudinal wave in vertical bar is not existent. In the case of welded bars with十geometry (Figs. $5 \& 6$ ), again there is no transmission into the vertical welding bars. However, the maximum values of the longitudinal elastic wave transmitted into the horizontal bar are about $99 \%$. This result is very close to the result obtained by $\mathrm{Wu}$ and Lundberg[4].

In this paper, we apply the theory to illustrating the bar with finite length. The phenomena of longitudinal wave propagation is merely to be discussed. Since the propagation velocity of longitudinal waves is larger than the transverse waves, the longitudinal waves certainly arrive at the end point of bar before the transverse waves. Furthermore, the longitudinal waves result in both the reflection and refraction waves in the bar. Therefore, if we want to consider the situation of transverse wave propagation in the bar with finite length, the more detail investigation is needed.

The values for the transmitted longitudinal waves $\bar{\phi}_{2}, \bar{\phi}_{3}$ and $\bar{\phi}_{4}$ are derived out in the present paper. Using the same method it would also be possible to derive values for other unknowns including $\phi_{R}$ (the reflected wave) and $\phi_{j}$ where $j$ refers to the $j^{\text {th }}$ welded bar at a junction at angle $\theta_{j}$ to the incident wave.

\section{APPENDIX}

The derivation process of Eqs. (46), (47), (71), (72), (73) and (74) is described as follows:

From Eq. (43), we obtain
$\bar{\phi}_{2}=\bar{Y}$

It follows from Eq. (44) that

$\bar{\phi}_{3}=-\bar{Y}$

From Eqs. (A-1) and (A-2), we acquire

$\bar{\phi}_{3}=-\bar{\phi}_{2}$

It is worth noticing that Eq. (A-3) is Eq. (46). The substitution of Eq. (A-3) into Eq. (33) yields

$\bar{T}_{3}=4 \rho C p L^{2} \bar{\phi}_{2}$

Similarly, we procure

$\bar{T}_{2}=-4 \rho C p L^{2} \bar{\phi}_{2}$

$$
\bar{T}_{1}=4 \rho C p L^{2}\left(\bar{\phi}_{I}-\bar{\phi}_{R}\right)
$$

From Eqs. (40), (41), and (42), we obtain, respectively,

$$
\begin{aligned}
& \bar{Q}_{1}=\left(\frac{\alpha P}{C L}\right)\left\{\frac{8 E L^{4}}{3} \bar{\theta}-\left(\frac{C L}{\alpha p}\right)^{1 / 2} \bar{M}_{1}\right\} \\
& \bar{Q}_{2}=\left(\frac{\alpha P}{C L}\right)\left\{\frac{8 E L^{4}}{3} \bar{\theta}-\left(\frac{C L}{\alpha p}\right)^{1 / 2} \bar{M}_{2}\right\} \\
& \bar{Q}_{3}=\left(\frac{\alpha P}{C L}\right)\left\{\frac{8 E L^{4}}{3} \bar{\theta}-\left(\frac{C L}{\alpha p}\right)^{1 / 2} \bar{M}_{3}\right\}
\end{aligned}
$$

Using Eqs. (A-1) (A-3) and Eqs. (A-8) and (A-9) and substituting the values of $\bar{Q}_{1}, \bar{Q}_{2}, \bar{Q}_{3}, \bar{Y}$ and $\bar{X}$, into Eqs. (37), (38) and (39), we get

$$
\begin{aligned}
& \bar{M}_{1}=\left(\frac{\alpha P}{3 C L}\right)\left\{8 E L^{4}\left(\bar{\phi}_{2}+\left[L+\left(\frac{C L}{\alpha p}\right)^{1 / 2}\right]\right) \bar{\theta}\right\} \quad \mathrm{A} \\
& \bar{M}_{2}=\left(\frac{\alpha P}{3 C L}\right)\left\{8 E L^{4}\left(\left[L+\left(\frac{C L}{\alpha p}\right)^{1 / 2}\right]\right) \bar{\theta}-\bar{\phi}_{I}-\bar{\phi}_{R}\right\}
\end{aligned}
$$

$$
\bar{M}_{3}=\left(\frac{\alpha P}{3 C L}\right)\left\{8 E L^{4}\left(\left[L+\left(\frac{C L}{\alpha p}\right)^{1 / 2}\right]\right) \bar{\theta}+\bar{\phi}_{I}+\bar{\phi}_{R}\right\}
$$


The substitution of Eqs. (A-10), (A-11) and (A-12) into Eq. (36) leads to

$$
\bar{\theta}=\frac{8 E L^{4}\left(2 L-\left(\frac{C L}{\alpha p}\right)^{1 / 2}\right)}{E L^{4}\left(6 L^{2}+7 L\left(\frac{C L}{\alpha p}\right)^{1 / 2}+\left(\frac{C L}{\alpha p}\right)\right)+2 \rho L^{5} P^{2}\left(\frac{C L}{\alpha p}\right)^{3 / 2}} \bar{\phi}_{2}
$$

Putting Eq. (A-13) into Eq. (35) yields

$$
\phi_{R}=-\frac{\left[6 \rho L^{3} P^{2}\left(\frac{C L}{\alpha p}\right)^{3 / 2}-2 \rho C P L^{2}\left(\frac{C L}{\alpha p}\right)^{3 / 2}+8 E L^{4}\right]}{\left[6 \rho L^{3} P^{2}\left(\frac{C L}{\alpha p}\right)^{3 / 2}+3 \rho C P L^{2}\left(\frac{C L}{\alpha p}\right)^{3 / 2}+8 E L^{4}\right]} \bar{\phi}_{I}
$$

The substitution of Eq. (A-14) into Eq. (35) yields

$$
\bar{\phi}_{2}=0
$$

It is worthy to point out that Eq. (A-15) is Eq. (47). In the same manner, we can prove Eqs. (71) (74)as follow

$$
\begin{aligned}
& \bar{\phi}_{3}=-\bar{\phi}_{2} \\
& \bar{\phi}_{2}=0 \\
& \bar{\phi}_{4}=-\bar{W}(p) p \bar{\phi}_{I}
\end{aligned}
$$

where

$$
\bar{W}(p)=\frac{\left(\frac{C L}{\alpha p}\right)^{3 / 2}}{\left[\frac{4}{3} C L^{2}+\frac{L p^{2}}{C}\left(\frac{C L}{\alpha p}\right)^{3 / 2}+\left(\frac{C L}{\alpha p}\right)^{3 / 2}\right]}
$$

It is deserving to point out that Eqs. (A-16) (A-19) is Eqs. (71) (74), respectively.

\section{REFERENCES}

1. Mandel, J.A., Mathur, R.K. and Chang, Y.C., "Stress Wave at Rigid Right Angle Joint," Journal of the Engineering Mechanics Division, ASCE, 97(4), 1173-1186 (1971).

2. Desmond, T.P., "Theoretical and Experimental Investi- gation of Stress Waves at a Junction of Three Bars," Journal of Applied Mechanics, ASME, 48, 148-152 (1981).

3. Simha, K.R.Y. and Fourney, W.L., "Investigation of Stress Wave Propagation Through Intersecting Bars," Journal of Applied Mechanics, ASME, 51, 345-353 (1984).

4. Wu, C.M. and Lundberg, B., "Reflection and Transmission of the Energy of Harmonic Elastic Waves in a Bent Bar," Journal of Sound and Vibration, 190(4), 645-659 (1996).

5. Atkins, K.J. and Hunter, S.C., "The Propagation of Longitudinal Elastic Waves around Right Angled Corners in Rods of Square Cross-section," Quarterly Journal of Mechanics and Applied Mathematics, 28, 245-260 (1975).

6. Achenback. J.D., Wave Propagation in Elastic Solids, 3rd Ed., North Holland Publishing Company, New York (1980).

7. Abramowitz, M. and Stegum, I.A., Handbook of Mathematical Function, Dover Publication, Inc. New York (1954).

\section{縱向彈性波在 $\mathrm{T}$ 型與十字型焊接桿件}

$$
\text { 之研究 }
$$

$$
\text { 梁明德陳秋鎮 }
$$

國立臺灣海洋大學河海工程研究所

$$
\text { 摘 要 }
$$

本文主要是探討交叉垂直焊接桿件中縱向彈性 波經由焊接點的透射問題, 經由横波及縱波方程式作 理論的推導, 並利用理論推導的結果應用在 $\mathrm{T}$ 型及十 字型交叉桿件上, 研究結果得知在 $\mathrm{T}$ 型的焊接桿件上 由水平桿入射縱向波經由焊接處透射至其他垂直桿件 上的透射縱波量值爲零; 當波通過十字型的垂直焊接 桿件上, 經由焊接處透射至其它垂直焊接桿件上的透 射縱波量值爲零, 水平焊接桿件的透射縱波量值大概 爲入射縱向波量值的 $99 \%$, 且原桿的反射縱向波量值 會存在。

關鍵字：入射、反射、透射。 